\title{
The Role of Spatial Modelling in Understanding Impacts of Climate Change on Temperature Patterns in Kenya
}

\author{
Emmanuel Yussuf \\ ${ }^{1}$ Department of Meteorology, University of Nairobi, Kenya
}

\begin{abstract}
While most developing countries contribute to less emission globally, the effects of climate change impact them more than the developed world, causing a rise in temperature over the years. These increasing temperatures cause more damage to economies and livelihoods over years as they lead to extreme weather events, in which developing countries are highly vulnerable. The use of spatial models such as GIS and satellite models are thus essential in forecasting future climate in relation to past information if well applied. This study aimed at finding out the role of spatial modelling in understanding temperature patterns in relation to climate change in Kenya. Mann-Kendall statistical method and modelling reanalysis were used to understand the relationship between observed and modelled temperature patterns from 1980 to 2015. A direct relationship between observed and modelled data was found, indicating that observations and models can give similar output of past climatic conditions under temperature parameter. On both scenarios, the average seasonal temperatures indicated an increasing rate on DJF and MAM seasons despite them being short and long rainy seasons respectively. This indicated that more practical sessions of observations and spatial modelling relationships could be done to understand past climate, and enhance newer models for forecasting future temperature patterns in Kenya and regionally.
\end{abstract}

Keywords: spatial modelling, temperature, climate change, reanalysis, GIS, forecasting, weather

\section{Introduction}

Climate change affects many parts of the globe. For us to understand the direction of future climate for mitigation and adaptation purposes, we need to have a better understanding of past climate and how it has changed so far from global and regional scales. Temperature change is a significant indicator in measuring climate change over decades and centuries [9].

The IPCC $5^{\text {th }}$ assessment report predicts that global surface temperature is likely to exceed $1.5^{\circ} \mathrm{C}$ by the end of $21^{\text {st }}$ century, relative to the period of 1850 to 1900 [8]. This can be mostly attributed to human influence through anthropogenic increase in greenhouse gas concentrations and other anthropogenic forcing, which lead to a rise in global mean surface temperature causing further warming and changes in all components of the climate system [8].

Geographical Information Systems (GIS) and modelling are becoming powerful tools in agricultural research and natural resource management, where spatial information on climate variables play an important role in understanding earth processes $[1,13]$. Synoptic climatology can be defined as a subject that combines atmospheric circulation with climate and other elements of the environment which enable the explanation and forecasting of many phenomena and processes in the atmosphere [15]. The use of GIS in climatology is to construct maps highlighting spatial properties of climate data, which can be valuable for analysing physical and human phenomena [2].

Kenya is already feeling the effects of climate change through the increasing average temperatures and changes in annual and seasonal rainfall. This is affecting key economic sectors, more so on agricultural production and tourism, health, water availability, energy use, infrastructure, biodiversity and ecosystem services. Wide spread poverty, frequent droughts and floods and few coping mechanisms all combine to increase the nation's vulnerability to climate change [10].

As much as modelling is used for understanding of the changing climate and predictions, users of the information should bear in mind that these models are not predictions of climate, but simulations of future climate under a range of hypothetical emission scenarios and thus interpretation should be with caution. Despite that, climate change is certainly taking place and over the coming decades, weather patterns will be less predictable [14].

Modelling of climate variables provides a better understanding of the world we are living in, for purposes of adaptation and mitigation in tackling climate change. However, these models have challenges in producing accurate information as weather and climate are dynamic and do not follow set rules. Information obtained from various methods such as satellites, can be used in giving outputs which will be of use in getting views of the changing climate over periods of time thus explaining certain phenomena as they occur. This study seeks to give an understanding of the role of modelling the impacts of climate change on temperature patterns in Kenya.

\section{Materials and Methods}

\subsection{Study Area}

Kenya's landscape rises from the Indian Ocean in the east to the edge of the East African Plateau and the Great Rift Valley in the west. The country straddles the equator, with a mean elevation of 762 meters, the highest point being Mt. Kenya at 5,199 meters. Kenya experiences a tropical climate varying according to topography where central highlands being cooler and the coast being warmer [17]. Kenya also lies within the Inter-Tropical Convergence Zone (ITCZ), 


\section{International Journal of Science and Research (IJSR) \\ ISSN: 2319-7064}

ResearchGate Impact Factor (2018): 0.28 | SJIF (2019): 7.583

which brings rain southwards from October to December and northwards from March to May [8].

Kenya's mean annual temperature has increased by 1 degree Celsius since 1960 , with rates of $0.29^{\circ} \mathrm{C}$ in MAM and $0.19^{\circ} \mathrm{C}$ in JJA seasons respectively [16].

\subsection{Materials}

This report utilized data from two different sources. Average monthly temperature data was obtained from globally available datasets derived from the Climate Research Unit (CRU), at the University of East Anglia, ranging from 1961 to 2016. This is historical data originating from observational datasets from different stations worldwide, which is then quality controlled for use in climate research [5].

A second dataset came from the Modern-Era Retrospective analysis for Research and Applications, version 2 (MERRA$2)$. This is a global atmospheric reanalysis produced by the NASA Global Modelling and Assimilation Office (GMAO), which provides regularly gridded highly spatial $\left(1 / 2^{\circ}\right.$ latitude by $5 / 8^{\circ}$ longitude) and temporal (hourly) resolution data, which comes in NetCDF format similar to that derived from CRU. This data is accessible online through NASA Goddard Earth Sciences Data Information Services Centre (GES DISC) [4].

\subsection{Methods}

In order to achieve the first specific objective, MannKendall test was conducted so as to determine the trend in seasonal and annual variations of temperature. This was done using MS Excel program to give the required output.

$$
S=\sum_{i=1}^{n-1} \sum_{j=k+1}^{n} \operatorname{sign}\left(x_{j}-x_{i}\right)
$$

For this test, null hypothesis states that there is no trend on the output from analysis, while the alternative hypothesis gives a trend that is either upward or downwards. If $S$ is greater than 0 , observations tend to be larger than those that appear in earlier times, and vice versa for $\mathrm{S}$ less than 0 .

A reanalysis of data obtained through MERRA-2 gave information for achieving the second specific objective. The output of this result was in form of maps for the country, showing changes in temperature nationally.

\section{Results and Discussion}

\subsection{Temperature Trends}

From the analysed data, it was observed (Fig 1) that annual temperatures increased from 1980 to 2016, with a positive trend, at a rate of about $3 \%$ per year. Observations were also noted on sharp descending in 1985, 1989, 2008 and slightly in 2013. This increase in temperature indicates significant warming of the country, which is consistent to the IPCC $4^{\text {th }}$ Assessment Report projections for eastern Africa [8]. This warming may lead to faster rates of evaporation and water shortages while affecting rainfall and drought in certain parts of the country [3].

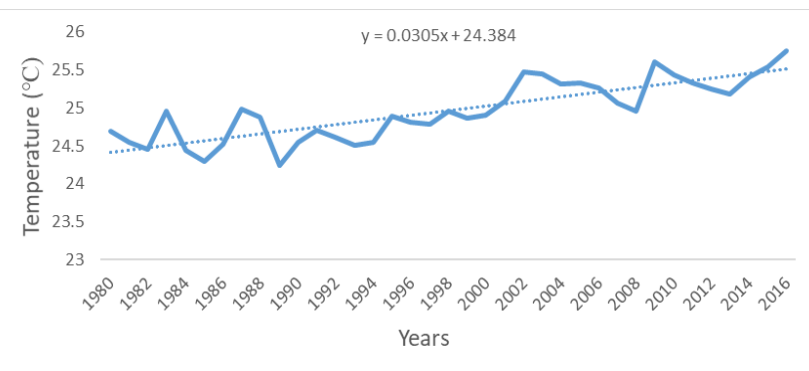

Figure 1: Annual temperature trend

Figure 2 gives the average temperature trends for the four seasons, i.e. March to May (MAM), June to August (JJA), September to November (SON) and December to February (DJF). It was observed that the rates of increase in temperature on all seasons were almost close to each other. DJF season recorded the highest growth rate $(3.2 \%)$ while SON recording the lowest rate $(2.7 \%)$, for the periods of 1980 to 2016. MAM season on the other hand also show a steady increase in temperature, which concurs with a UNICEF report that notes the same, despite it being the planting and long rains season [14].
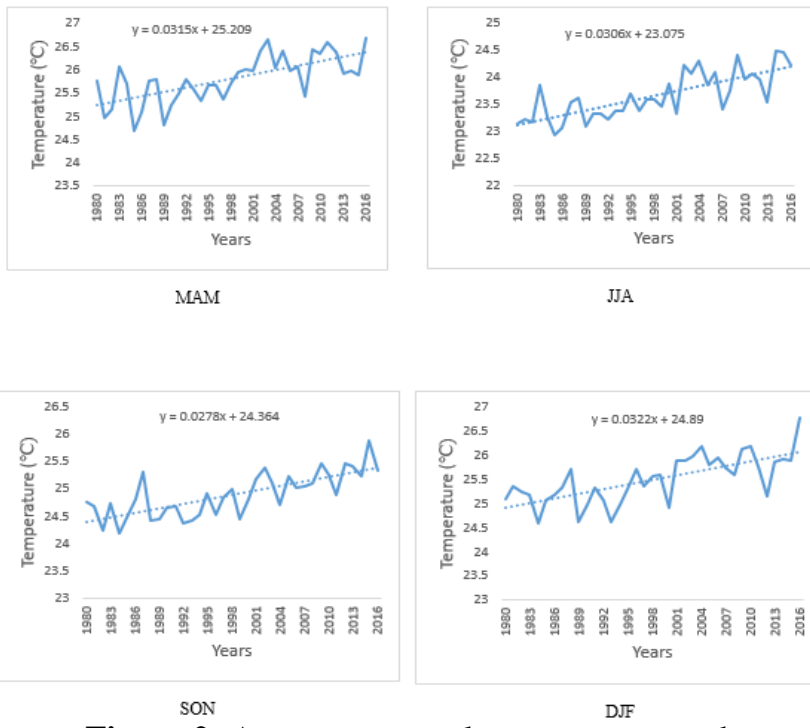

Figure 2: Average seasonal temperature trends

\subsection{Modelled Results}

Modelled results were obtained from reanalysis of data through the MERRA-2 model. This gave an output in form of maps to describe the changing seasonal temperatures from 1980 to 2015 .

Figure 3 shows the average seasonal temperatures as modelled by MERRA. It was observed that certain parts of the country had an almost constant change in temperature in all four seasons. The North Eastern part of Kenya showed high rates of increase in temperatures during MAM and DJF seasons, while a slower rate during JJA and SON, which happen to be cold seasons. Turkana county and areas surrounding it show a higher rate of increase in temperature over the study period, which is similar to a survey conducted by Human Rights Watch that showed the same results [6]. It can however be noted that the central and rift valley regions show very little changes in average seasonal temperatures 


\section{International Journal of Science and Research (IJSR) \\ ISSN: 2319-7064}

ResearchGate Impact Factor (2018): 0.28 | SJIF (2019): 7.583

over the 35-year study period. Lowest rates of temperature change are recorded in this regions over JJA season as it happens to be Kenya's winter or colder season. Thus, Kenya's plateaus and mountain ranges are likely to continue being cooler than surrounding lowlands amidst the increasing warm temperatures experienced on the rest of the country [3].

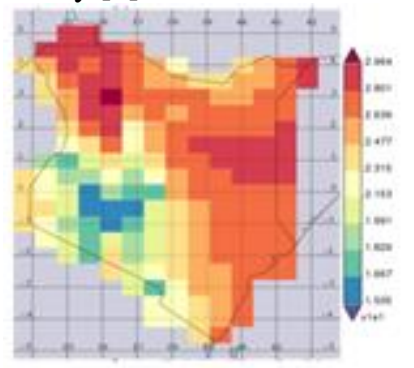

Mest

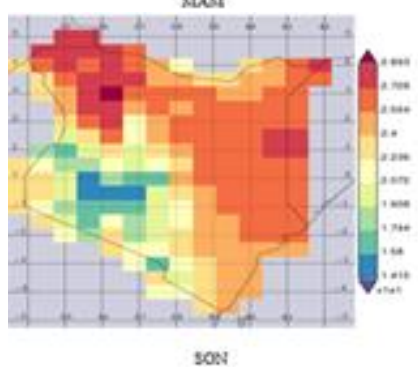

5004

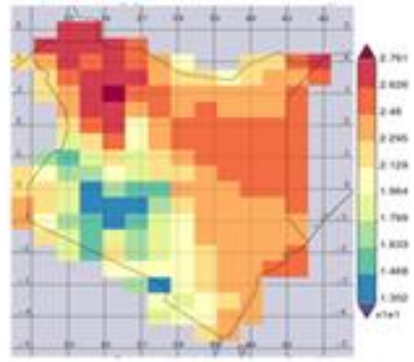

ra

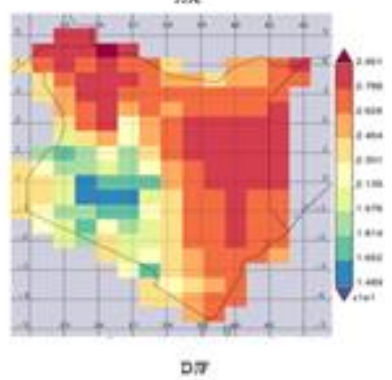

$\mathrm{D} \pi$
Figure 3: Average seasonal temperature (MERRA - 2)

Figure 4 shows the average seasonal temperatures obtained from MERRA-2 reanalysis model. The results concur with those from CRU, where we observe that DJF and MAM seasons show the highest temperature growth over time while JJA shows the least change as it is a colder season. From the diagram, it can also be noted that there was a sharp decline in temperature in DJF season over 1998. This can be attributed to the El-Nino Southern Oscillation (ENSO) that took place at the time causing flooding and a colder season. Temperature can thus be observed to be rising, though slow and steadily, over the years with more increase over certain seasons compared to others. Highlands are also observed to maintain slow rates of temperature increase compared to flat lands and the coastal region.

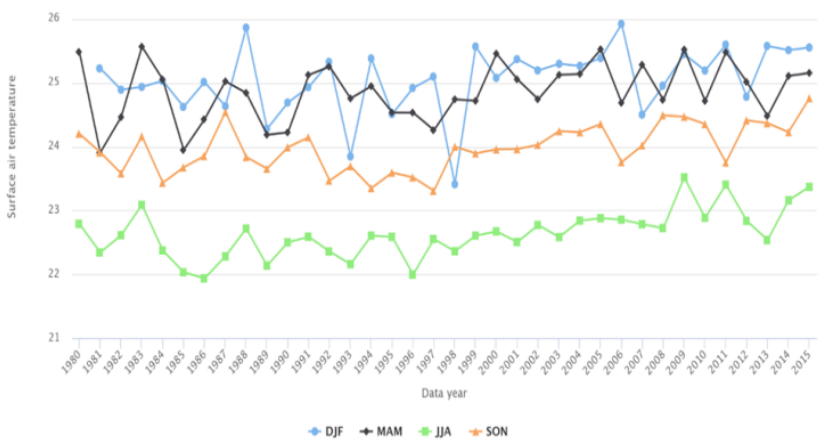

Figure 4: Average seasonal temperature observations (MERRA -2)

\section{Conclusions}

We have observed that models from satellites correlate with information obtained from observational sources. Since climate change is a global problem, the use of models both from satellite reanalysis and GIS are useful in understanding the climate nationally, and explaining in detail climate parameters as they change over time, more so temperature. Average temperatures nationally can be distinguished regionally within the country as modelling gives outputs in form of maps that can explain each area more distinctively to another.

The impacts of rising temperatures will likely cause more harm as their will be increased frequency of extreme weather events witnessed across the country, varying from one place to another. Studies of climate variability locally are important in planning and management of natural resources among others [11]. In order to tackle this problem, relating models and observational data is important for improving forecasting, which can be useful in reducing future climate damages.

\section{Other recommendations}

This study report recommends further studies on relating climate observations and models such as satellite reanalysis and GIS, in getting a better view on how climate is changing regionally and nationally. This will be useful in forecasting the climate of our nation alongside RCPs. Furthermore, it also recommends a national database of climate data of each region/location within the country for use in modelling and accurate analysis and forecasting.

\section{References}

[1] Abu, S., \& M., A. A. (2016). Geospatial Modeling for Investigating Spatial Pattern and Change Trend of Temperature and Rainfall. Climate, 4, 21; doi:10.3390/cli4020021.

[2] Esteban, P., \& M. Ninyerola, a. M. (2009). Spatial modelling of air temperature and precipitation for Andorra (Pyrenees) from daily circulation patterns. Springer, 96:43-56.

[3] FEWS-NET. (2010). A Climate Trend Analysis of Kenya-August 2010. Nairobi: Famine Early Warning Systems Network Informing Climate Change Adaptation Series.

[4] Galero, R., \& Others. (2917). The Modern-Era Retrospective Analysis for Research and Applications, Version 2 (MERRA-2). Journal of Climate.

[5] Harris, I., Jones, P., Osborn, T., \& Lister, D. (2014). Updated high-resolution grids of monthly climatic observations - CRU TS3.10: The Climatic Research Unit (CRU) Time Series (TS) Version 3.10 Dataset. International Journal of Climatology, 34, 623-642.

[6] HRW. (2015). "There is No Time Left": Climate Change, Environmental Threats, and Human Rights in Turkana County, Kenya. Human Rights Watch.

[7] IPCC. (2007). AR4 Climate Change 2007: Synthesis Report. Intergovernmental Panel on Climate Change.

[8] IPCC. (2013). Climate Change 2013: The Physical Science Basis. Intergovernmental Panel on Climate Change.

[9] Karl, T. R., Easterling, D. R., Horton, B., Jones, P. D., Peterson, T. C., Parker, D. E., . . . Folland, C. K. (1997). Maximum and Minimum Temperature Trends for the Globe. Science, pp. 364-367.

\section{Volume 9 Issue 7, July 2020


[10] NEMA. (n.d.). Climate Change in Kenya. Retrieved May 12, 2020, from http://meas.nema.go.ke/unfccc/climate-change-inkenya/

[11] Opiyo., F., Nyangito, M., Wasonga, O. V., \&Omondi, P. (2014). Trend Analysis of Rainfall and Temperature Variability in Arid Environment of Turkana, Kenya. Environmental Research Journal, 30-43.

[12] Robert W., P., \& Susan, S. a. (2009). Spatial and seasonal patterns in climate change, temperatures, and precipitation across the United States. PNAS, Vol 6, No 18.

[13] Samanta, S., Pal, B., \& Pal, D. K. (2011). Modeling of Monthly Mean Air Temperature through Remote Sensing and GIS techniques. International Journal of Advances in Science and Technology, Vol 3, No 1.

[14] UNICEF. (2010). CLimate Change in Kenya: Focus on Children. Nairobi: United Nations Children Education Fund.

[15] Ustrnul, Z. (2006). Spatial differentiation of air temperature in Poland using circulation types and GIS. International Journal of Climatology, 26(11):1529 1546.

[16] World Bank, Climate Knowledge Portal. https://climateknowledgeportal.worldbank.org/country/ kenya/climate-data-historical

[17] The World Factbook 2020. Washington, DC: Central Intelligence Agency, 2020. https://www.cia.gov/library/publications/resources/theworld-factbook/index.html

\section{Author Profile}

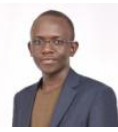

Emmanuel Yussuf has a BSc in Meteorology, and currently pursuing an MSc in Climate Change from the University of Nairobi. He has deep interests in climate change, urban planning, air and noise pollution, climate smart cities and information technology. 